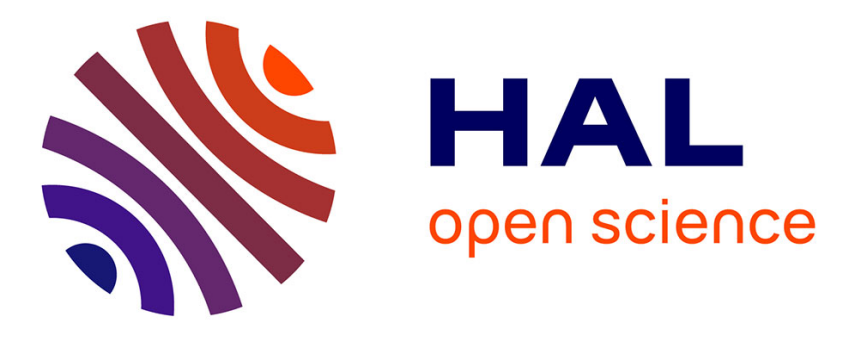

\title{
Polariton effects in the resonant emission of $\mathrm{KI}$
}

\author{
A. Nouailhat, G. Guillot, E. Mercier, Truong van Khiem
}

\section{To cite this version:}

A. Nouailhat, G. Guillot, E. Mercier, Truong van Khiem. Polariton effects in the resonant emission of KI. Journal de Physique Lettres, 1978, 39 (13), pp.223-225. 10.1051/jphyslet:019780039013022300 . jpa-00231484

\section{HAL Id: jpa-00231484 https://hal.science/jpa-00231484}

Submitted on 1 Jan 1978

HAL is a multi-disciplinary open access archive for the deposit and dissemination of scientific research documents, whether they are published or not. The documents may come from teaching and research institutions in France or abroad, or from public or private research centers.
L'archive ouverte pluridisciplinaire HAL, est destinée au dépôt et à la diffusion de documents scientifiques de niveau recherche, publiés ou non, émanant des établissements d'enseignement et de recherche français ou étrangers, des laboratoires publics ou privés. 


\author{
Classification \\ Physics Abstracts \\ $71.36-78.55-78.60 \mathrm{H}$
}

\title{
POLARITON EFFECTS IN THE RESONANT EMISSION OF KI
}

\author{
A. NOUAILHAT, G. GUILLOT, E. MERCIER and TRUONG VAN KHIEM
}

\author{
Laboratoire de Physique de la Matière $\left({ }^{*}\right)$ \\ Institut National des Sciences Appliquées de Lyon \\ 20, avenue Albert-Einstein, 69621 Villeurbanne Cedex, France
}

(Reçu le 5 avril, révisé le 17 mai 1978, accepté le 22 mai 1978)

\begin{abstract}
Résumé. - Sous irradiation électronique, on observe l'émission résonnante analogue à celle obtenue sous excitation optique dans la première bande d'absorption. L'analyse de ses propriétés en fonction de la profondeur de pénétration du faisceau électronique dans le cristal semble montrer un effet de transparence induite par effet polariton.
\end{abstract}

Abstract. - We have observed resonant emission in a KI crystal under electron irradiation similar
to that obtained with U.V. excitation on the first exciton absorption band. Its properties as a function
of the penetration depth of electrons in the crystal might be due to a polariton induced transparency.

Measurements on the narrow band edge luminescence in alkali halides are just beginning, but they have already provided important information on the existence of the free exciton and its relaxation processes [1-5]. Nevertheless, free exciton dynamics are not yet well understood; one of the main problems is the polariton propagation mode in the crystal and its interaction with defects. We have undertaken studies on the resonant luminescence of alkali iodides excited by UV light and also by electrons, to be able to vary the depth of the excited layer between about one micron and ten microns. The electron beam is also used to introduce a given concentration of defects in a well defined layer. Nominally pure single crystals of $\mathrm{KI}$ and $\mathrm{RbI}$ obtained from the Crystal Growth Laboratory of the University of Utah (USA) are cleaved about $1 \mathrm{~mm}$ thick and mounted on the cold finger of a helium cryostat in a dry atmosphere. The luminescence is excited in the high energy side of the first excitonic absorption peak with a $200 \mathrm{~W}$ deuterium lamp (manufactured by original Hanau) through a grating monochromator (Hilger and Watts D 292), or with a pulsed electron beam, the energy of which is between 10 and $60 \mathrm{kV}$. The apparatus has been described elsewhere [6]: The luminescence collected from the excited surface of the sample is analysed with a grating monochromator (Mac Pherson 218 A equipped with a 2400 grooves $/ \mathrm{mm}$ grating - resolution $13.25 \AA / \mathrm{mm} \longrightarrow$ ) and detected by a 9813 QB EMI

(*) Equipe de recherche associée au C.N.R.S. photomultiplier followed by a Brookdeal lock-in amplifier.

Experimental results. - Two geometric configurations have been used : electron excitation and observation normal to the sample surface, and observation normal to the excitation, the crystal being at $45^{\circ}$ to the excitation as shown in figure 1 . The measured emission spectra are the same for both configurations. The maximum energy and width at halfheight of the edge emission near liquid helium temperature are given in table I. It is the same as obtained under UV excitation, and different to that obtained under X-ray excitation $(5.79 \mathrm{eV}$ and $5.69 \mathrm{eV}$ respectively for $\mathrm{KI}$ and $\mathrm{RbI}$ at $5 \mathrm{~K}$ [4]). These differences can be attributed to the difference in the excitation mode. X-rays dissipate their energy deep into the crystal contrary to UV or electrons. The resonant emission line is not observed, and only broadrising and shifted emission to lower energy is recorded. The behaviours of the emissions are identical considering the temperature under UV and electron excitation in agreement with other results $[3,5]$. We have also done a measurement of the resonant luminescence lifetime $\tau_{\mathrm{R}}$ of $\mathrm{KI}$ at $8 \mathrm{~K}$ using an ATNE boxcar (gate width $1 \mathrm{~ns}$ ) : lifetime $\tau_{\mathbf{R}}$ has been found to be shorter than that of the $\sigma$ emission (which represents the limit of our apparatus) : $\tau_{\mathrm{R}}<2.5 \mathrm{~ns}$.

The properties of the resonant emission for KI at $8 \mathrm{~K}$ with the electron irradiation conditions are as follows : the ratio $I_{\mathrm{R}} / I_{\sigma}$, where $I_{\mathrm{R}}$ is the intensity of the resonant emission and $I_{\sigma}$ the intensity of the $\sigma$ component of the 
TABLE I

\begin{tabular}{|c|c|c|c|c|c|c|}
\hline \multirow[t]{2}{*}{ Excitation } & \multicolumn{2}{|c|}{ UV } & \multicolumn{2}{|c|}{ Electrons } & \multicolumn{2}{|c|}{$X$ rays [4] } \\
\hline & $E_{\mathrm{R}}(\mathrm{eV})$ & $\Delta E(\mathrm{meV})$ & $E_{\mathrm{R}}(\mathrm{eV})$ & $\Delta E(\mathrm{meV})$ & $E_{\mathrm{R}}(\mathrm{eV})$ & $\Delta E(\mathrm{meV})$ \\
\hline$\overline{\mathrm{KI}}$ & & & & & & \\
\hline $\begin{array}{l}\mathrm{KI} \\
\mathrm{RbI}\end{array}$ & $\begin{array}{l}5.84[4] \\
5.734\end{array}$ & $\begin{array}{l}\leqslant 14 \\
\leqslant \quad 1\end{array}$ & $\begin{array}{l}5.835 \\
5.734\end{array}$ & $\begin{array}{l}\leqslant 2 \\
\leqslant 1\end{array}$ & $\begin{array}{l}5.79 \\
5.69\end{array}$ & $\begin{array}{l}35 \\
35\end{array}$ \\
\hline
\end{tabular}

$E_{\mathrm{R}}$ : energy of the maximum; $\Delta E$ : width at halfheight.

self trapped exciton emission, is constant if the instantaneous intensity of the current density varies over two orders of magnitude $\left(0.1-10 \mu \mathrm{A} / \mathrm{cm}^{2}\right.$ - average energy dissipation rate of $\left.1.3 \times 10^{19} \mathrm{eV} / \mathrm{cm}^{3} \times \mathrm{s}\right) . I_{R}$ is very sensitive to defects : the introduction of $10^{17} \mathrm{~F}$ centres $/ \mathrm{cm}^{3}$ by irradiation at $120 \mathrm{~K}$ quenches completely the resonant emission (whereas the intensity of the $\sigma$ component has decreased by about $10 \%$ ). We have measured the ratio $I_{\mathrm{R}} / I_{\sigma}$ as a function of the electron energy between 10 and $60 \mathrm{keV}$, i.e. for a penetration depth $x_{0}$ between 1.7 and $19 \mu$ [7] (Fig. 1),

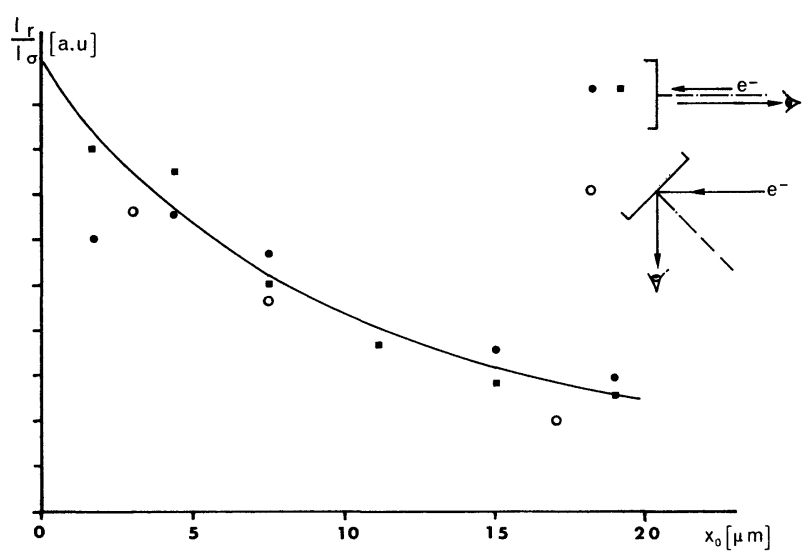

FIG. $1 .-I_{\mathbf{R}} / I_{\sigma}$ versus $x_{0}, T=8 \mathrm{~K} . I_{\mathrm{R}}$ : resonant emission intensity. $I_{\sigma}: \sigma$ component intensity of the self trapped exciton emission. $x_{0}$ : penetration depth of electrons. $O, \bullet, \square$ : experimental results.

$$
\text { - }: \frac{1-\exp -u}{u} \text { with } u=\frac{x_{0}}{R_{0}}, \cdot R_{0}=5 \mu \mathrm{m} .
$$

$I_{\mathrm{R}} / I_{\sigma}$ decreases by a factor of about 2 when $x_{0}$ increases by a factor of 10 . Since the $\sigma$ emission originates from the whole excited volume, without absorption by the crystal, we can conclude that the resonant luminescence is produced in the volume rather than on the surface of the crystal. Consequently, the absorption for $I_{\mathrm{R}}$ seems anomalously small if we consider that the difference between the peak of the emission $E_{\mathrm{R}}$ and the first exciton absorption peak $E_{\mathrm{a}}$ is about $10 \mathrm{meV}$ [8] : if we suppose that the emission $I_{R}$ is isotropic [3] in the excited layer, the thickness of which is $x_{0}$ and that we can define an absorption coefficient $1 / R_{0}$ for photons of energy $E_{\mathrm{R}}$, it is easy to show that the ratio $I_{\mathrm{R}} / I_{\sigma}$ should vary as $(1-\exp -u) / u$ where $u=x_{0} / R_{0}$. Using our experimental data, we obtain an order of magnitude for $1 / R_{0} \simeq 10^{3} \mathrm{~cm}^{-1}$; on the other hand, the absorption coefficient at $E_{\mathrm{a}}$ measured by conven- tional absorption is certainly larger than $10^{5} \mathrm{~cm}^{-1}$. These results have been obtained with different materials and cannot provide a positive proof for an anomalous behaviour, contrary to the following experiments : defects created by ionizing radiation in alkali halides are known to quench the intrinsic luminescence [9-11]. We have created defects in a $1.7 \mu \mathrm{m}$ thick layer by irradiation at $120 \mathrm{~K}$, and afterwards we measured the excitation spectrum of the $\pi$ intrinsic component around the first exciton absorption peak region up to $2130 \AA$, and we observed that UV light is unable to excite the customary $\pi$ luminescence. This shows that the range for $2125 \AA$ photons is smaller than $1.7 \mu$. Moreover, if we excite the same crystal with $60 \mathrm{kV}$ electrons (over $19 \mu$ range), we cannot detect any resonant luminescence whereas the $\sigma$ component is only $10 \%$ smaller than in the virgin crystal. The layer of defects inhibits completely the $2125 \AA$ emission. This shows that the resonant energy $E_{\mathrm{R}}$ does not behave in the crystal like an ordinary photon.

Discussion. - We deduce from our investigations that the energy $E_{\mathrm{R}}$ corresponding to the resonant emission is able to propagate in the virgin crystal over a large range. We suggest that we are observing a polariton effect, and it might be the first direct evidence for such an effect recently discussed by Fontana [12]

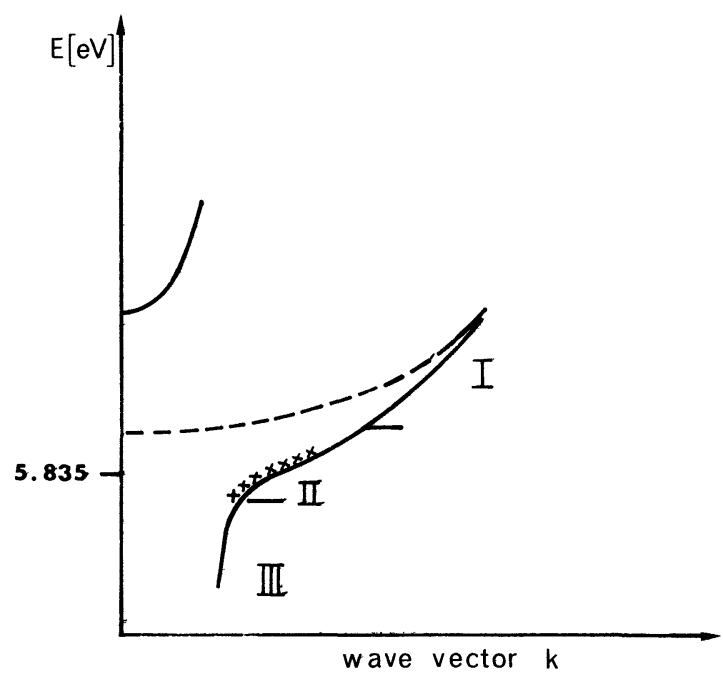

Fig. 2. - Diagram of the dispersion curve of the exciton polariton - _ - : uncoupled free exciton (non relaxed exciton) I, II and III are the three energy ranges (see text) $x x x x x$ : approximate location of the bottleneck. 
in the alkali halides. Similar conclusions have been made for ZnSe by Sermage et al. [13] using a similar method, and for $\mathrm{CdS}$ [14], $\mathrm{Cu}_{2} \mathrm{O}$ [15] and GaSe [16] from direct absorption measurements, in spite of some criticisms [17].

The excitations of a polar crystal (the excitons and phonons) are strongly coupled to the electromagnetic field [18]. These mixed excitations are called polaritons and can be regarded as exciton-like or photon-like depending on the considered energy region. The dispersion curve of the polariton consists of two branches, with a peculiar region of anticrossing in which the exciton photon mixing is the largest (Fig. 2). This region of bottleneck (region II, Fig. 2) gives rise to the processes of resonant exciton absorption and emission of light by the crystal [19].
In the process of exciton emission, the polariton wave, which is propagating inside the crystal, reaches the crystal boundary and there changes into a photon which can be detected as the resonance emission.

When defects or impurities are in the path of the polaritons, their energy is dissipated and does not give resonance luminescence which explains its high sensitivity to the defects. In conclusion, it seems that cathodoexcitation is a very good tool to investigate polariton effects in alkali halides directly in the bulk crystal. This avoids all the complications inherent in using the thin films which are necessary for optical absorption spectroscopy, and permits precise measurements of defect-polariton interactions.

\section{References}

[1] Kuusmann, I. L., Liblik, P. Kh., Lushchik, Ch. B., JETP Lett. 21 (1975) 72.

[2] Liblik, P. Kh., LiID'ya, G. G., LushchiK, N. E., LushChIK, Ch. B., Soovik, T. A., Sov. Phys. Solid State 17 (1976) 2312.

[3] Nishimura, H., Ohigashi, C., Tanaka, Y., Tomura, M., J. Phys. Soc. Jpn 43 (1977) 157.

[4] Hayashi, T., Ohata, T., Koshino, S., J. Phys. Soc. Jpn 42 (1977) 1647 ;

Hayashi, T., Ohata, T., Koshino, S., J. Phys. Soc. Jpn 43 (1977) 347.

[5] Guillot, G., Mercier, E., Nouailhat, A., J. Physique Lett., 38 (1977) L495.

[6] Mercier, E., Guillot, G., Nouallhat, A., Rev. Phys. Appl. 12 (1977) 61

[7] Herrmann, F., Pinard, P.. J. Phy's. C 3 (1970) 1037

[8] Tomiki, T., Miyata, T., Tsukahoto, H. Z., Z. Naturforsch. 29A (1974) 145.

Tomiki, T., MiYata, T., Tsukahoto, H., J. Phys. Soc. Jpn 35 (1973) 495.
[9] Guillot, G., Nouallhat, A., Mercier, E., Pinard, P., J. Lum 12-13 (1976) 317.

[10] Nouallhat, A., Guillot, G., Mercier, E., Solid State Commun. 21 (1977) 725.

[11] Hayashi, T., J. Phys. Soc. Jpn 43 (1977) 1694.

[12] Fontana, M. P., Phys. Rev. Lett., 37 (1976) 789.

[13] Sermage, B., Blanconnier, P., Proceeding of the 13th International Congress in Semiconductors, Rome, 1976; Sermage, B., Voos, M., Phys. Rev. B 15 (1977) 3935.

[14] Voigt, J., Phys. Status Solidi (b) 64 (1974) 549.

[15] Kreingold, F. I., MaKarov, V. L., JETP Lett. 20 (1974) 201 ; Kreingold, F. I., Makarov, V. L., Sov. Phys. Solid State 17 (1975) 297.

[16] Bosacchi, A., Bosacchi, B., Franchi, S., Phys. Rev. Lett. 36 (1976) 1086.

[17] Besson, J. M., Le Toullec, R., Piccioli, N., Phys. Rev. Lett. 39 (1977) 671.

[18] Hopfield, J. J., Phys. Rev. 112 (1958) 1555.

[19] Toyozawa, Y., Prog. Theor. Phys. Suppl. 12 (1959) 111. 